\title{
Un accidente de tránsito visto a través de los ojos del chamanismo amazónico
}

\section{Juan Felipe Guhl Samudio}

(iD) https://orcid.org/0000-0001-7180-7125

Instituto Amazónico de Investigaciones Científicas SINCHI, Colombia

jfguhl@gmail.com

RESUMEN

Este trabajo se desarrolló con las comunidades indígenas del río Miriti-Paraná, un pequeño afluente del río Caquetá (Japura), en el noroccidente de la cuenca amazónica en Colombia. Lo que presento a continuación es el itinerario terapéutico de Enio Yukuna, un hombre mayor que sufrió un accidente de tránsito y que al momento de relatar lo que le había ocurrido se remontó en su memoria varias décadas atrás para explicar que el principio de su mal se dio cuando fue a cazar a una danta (tapir) en un salado. Su itinerario y la narración del suceso es pertinente, pues habla de la forma en que se concibe el territorio, la cosmopolítica, los procesos ontológicos para aprender el chamanismo y también de la interacción con la biomedicina y el sistema médico occidental. Así, este hombre hace explicitos los procesos propios de curación que se dan en su área geográfica, pasando por chamanes de diferentes etnias y variados conocimientos y que se comportan de manera distinta ante su mal. Habla también de la complementariedad de género con su mujer $y$ de los prejuicios hacia la migración de los jóvenes, y finalmente cuenta cómo fue remitido a Bogotá para ser atendido por su dolencia. Es una narración de gran riqueza y complejidad que nos da la posibilidad de navegar por los diversos universos amazónicos con relación a la salud de un individuo. 
Palabras clave: chamanismo, itinerario terapéutico, ontología, autoatención, intermedicalidad, Mirití-Paraná, Yukuna, modelo explicativo.

\title{
A traffic accident seen through the eyes of Amazonic shamanism
}

\author{
ABSTRACT
}

This work was carried out with the indigenous community of the Miriti-Parana river, a short tributary of the Caquetá (Japura) river, located northwest of Colombia's Amazon basin. I set forth the therapeutic journey of Enio Yukuna, an old man who had a traffic accident and, when telling the story of what happened, recalled that his misfortune began some decades ago when he went tapir hunting in a clay lick. His story and journey are relevant because he talks about how he conceives the land, cosmopolitics, the ontological processes to learn shamanism, and of the interaction of biomedicine and the Western medical system. In doing so, he speaks explicitly of the typical healing processes that take place in his region, going through shamans of different ethnic groups and varied knowledge that behave in different ways vis-à-vis his affliction. He also talks about gender complementarity with his wife and about prejudice against youth migration, and finally tells how he was sent to Bogota to be treated for his ailment. It is an incredible story that gives us the opportunity to explore the multiple Amazonic universes regarding a person's health.

Keywords: shamanism, therapeutic itinerary, ontology, self-care, intermedicality, Mirití-Paraná, Yukuna, explanatory model. 


\section{INTRODUCCIÓN}

Este artículo es un aporte de la antropología al área de la salud a través de un itinerario de enfermedad de un hombre indígena amazónico: Enio Yukuna, quien sufrió un accidente de tránsito en la ciudad de Leticia (Amazonas, Colombia) en el año 2018. En su relato de la enfermedad, Enio viaja hacia atrás en el tiempo para mostrar que el mal que lo aqueja proviene de las entidades espirituales de su territorio. Así, se narra un camino para intentar solventar la crisis de salud que lo lleva a redes y sistemas chamánicos de su región, que a su vez complejizan sus prácticas de autoatención. Y aunque él se encuentre en un tratamiento biomédico en el cual le han realizado las cirugías correspondientes, su problema de salud trasciende el malestar fisiológico y en su narrativa se deja ver la necesidad y la importancia que representa el poder acudir a una red de sabedores con conocimientos comunes para sobrellevar mejor su padecimiento.

Enio Yukuna vivió gran parte de su vida en el resguardo del Mirití-Paraná (ver mapa 1), al suroriente de la República de Colombia y al noroccidente de la cuenca amazónica. Este resguardo está habitado mayoritariamente por las etnias yukuna y matapí — del tronco lingüístico arawak — y taminuka y letuama - del tronco lingüístico tukano-, pero también hay representantes de las etnias cubeo, murui $^{1}$, yauna, makuna, miraña, bora y cabillari, entre otras. Según cifra del Departamento Nacional de Estadística, hay una población aproximada de 1318

Empleo la denominación murui en lugar de huitoto, uitoto, witoto, siguiendo la preferencia de los mismos indígenas de esa etnia (ver Agga, Wojtylak y Echeverri, 2019, para una explicación detallada). 
habitantes ${ }^{2}$. Al sentarme a conversar con los chamanes ${ }^{3}$ de las distintas etnias, me enteré de que, aunque estos grupos se diferencian en varios aspectos, los caminos de curación —lawichú — son los mismos, pero con «ramas» disímiles para cada uno, como un río de común navegación para todos los chamanes y que puede ser transitado por brazuelos específicos dependiendo de los conocimientos para la curación a realizar, convirtiéndose en una red chamánica de la región.

Las comunidades de esta zona son multiétnicas y dispersas. Por lo general, existe una maloca habitada por el chamán y su familia y algunos núcleos familiares de su descendencia. Esta maloca a su vez es el ente aglutinador de los demás pobladores quienes usualmente ubican sus viviendas en lugares cercanos.

Figura 1. Resguardos y etnias indígenas en los interfluvios de los ríos Caquetá, Mirití-Paraná y Apaporis

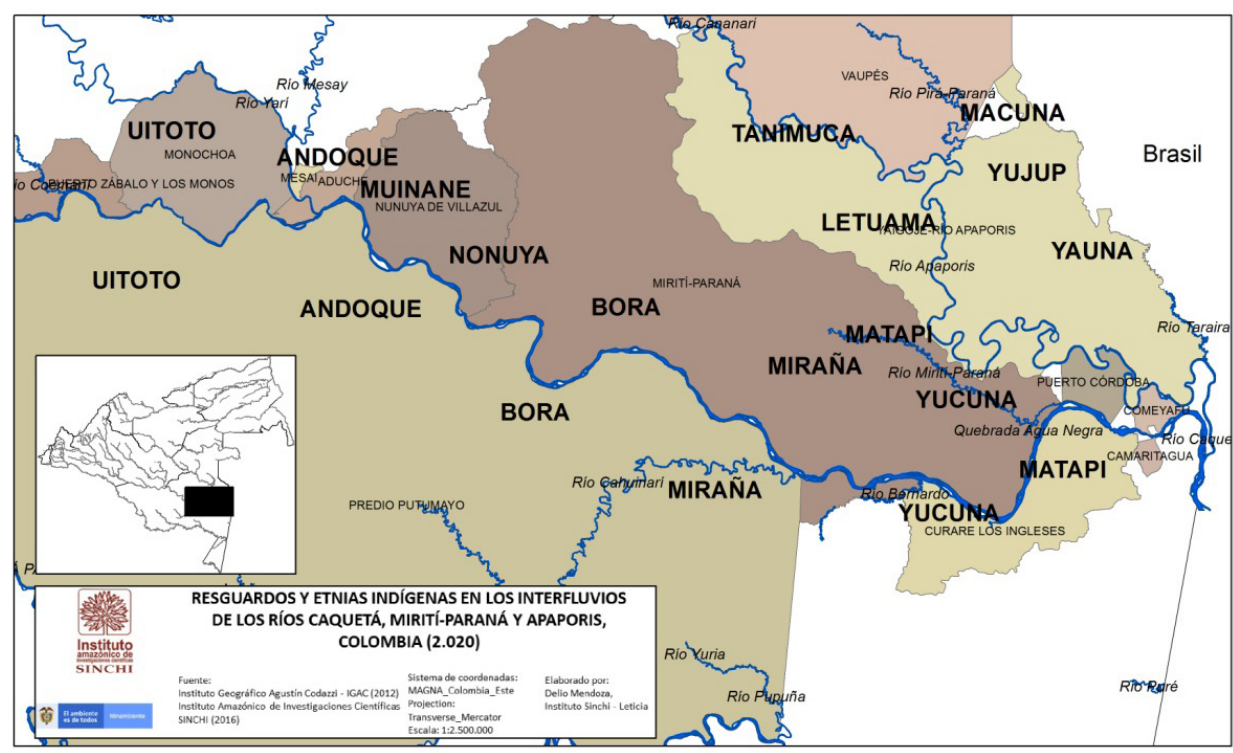

Fuente: Grupo de Investigación Valoración de los Conocimientos Tradicionales, Instituto Sinchi 2020. Elaborado por Delio Mendoza.

2 https://www.dane.gov.co/index.php/estadisticas-por-tema/demografia-y-poblacion/gruposetnicos/informacion-tecnica

3 La primera vez que estuve en el río Mirití fue en el año 2004 y desde entonces he podido visitar las comunidades de forma intermitente. Los trabajos que he realizado son Guhl, 2005, 2008, 2018. 
En el chamanismo del que se habla en este artículo, uno de los temas centrales es el concepto de pechují, que quiere decir «pensamiento-alma» y que se podría explicar como la esencia que poseen los animales, objetos inanimados y personas. En la naturaleza todo posee su propio pechují haciendo que el cosmosmundo y sus lugares estén conformados tanto por los pensamientos-almas de las entidades espirituales - que tienen sus malocas y su gente-, espíritus errantes, objetos mágicos y los demás seres de la naturaleza, lo que se ha llamado humanos-verdaderos, humanos-animales/vegetales y otras formas animadas, como la enfermedad. Los chamanes pueden adherir a su cuerpo múltiples pechujís, pero a la vez este puede ser robado o intercambiado de otras personas, animales, plantas y entidades, lo que produce enfermedades de distinta índole causadas por los jarechinas (entidades espirituales), los animales o los «dueños» de otros mundos que suben y bajan para conseguir su cacería, es decir, el pechuji de los humanos. Todo este sistema está relacionado con los lazos de reciprocidad y las alianzas entre las malocas, tanto físicas como espirituales, ya que es con sus dueños con quienes se negocia para adquirir el alimento como prevención para no enfermar. Igualmente, las personas, además de su pechují, tienen un recubrimiento espiritual que es llamado na 'mácana — camisa—, que al ser rasgada o agujereada hace que los individuos enfermen, con la posibilidad de ser curados por los chamanes que poseen la habilidad de realizar «remiendos». Estas na'mácana también simbolizan las especialidades en brujería que tienen los individuos y que son utilizadas por ellos para emprender sus viajes en los caminos de pensamiento lawichú y mantener la salud de la comunidad a través de los rituales y prevenciones que se hacen a diario y en momentos determinados del camino de curación del tiempo.

Para este trabajo, los conceptos de médico tradicional, maloquero y brujo se usan sin distinción y hacen referencia al chamán en los términos utilizados en el río por las etnias. Para el caso de los yukuna-matapí, existen chamanes que se clasifican por su especialidad: lawichura' $a$, que hace referencia a los chamanes que curan e identifican enfermedad mediante el cuerpo - es decir, por medio de la oración - y que son la gran mayoría; mari'chu, chamanes que «miran» y andan con el «pensamiento», y ojomi, referido a los chamanes que recorren el mundo en forma de tigre hombre/jaguar. Todos los chamanes tienen el carácter ambivalente de curar y enfermar o hacer conjuros y males a las personas.

Hoy en día existe una fuerte migración desde las comunidades del río Mirití hacia otros centros poblados, lo que ha llevado a que muchos indígenas residan en otros lugares. Es el caso de Enio, el protagonista de nuestra historia, quien por la ausencia de sus hijos prefirió irse a vivir a Leticia, capital del departamento 
del Amazonas, donde algunos de ellos habían decidido mudarse. De esta manera los conocimientos y prácticas se van relocalizando y adaptando a sus nuevos entornos.

\section{EL ACCIDENTE DE TRÁNSITO DE ENIO YUKUNA}

En Bogotá, buscando narrativas sobre la pluralidad médica, decidí investigar si se encontraba algún indígena remitido en la capital por alguna dolencia para que me relatara su experiencia y así comprender mejor cómo funcionan los itinerarios terapéuticos y la intermedicalidad. Me comuniqué entonces con Horacio Yukuna, auxiliar de enfermería en el Mirití, y con el promotor de Mallamas, empresa prestadora de salud indígena. Ellos me informaron que Enio Yukuna, indígena oriundo de esta zona amazónica, se encontraba internado en esos momentos en el Hospital Universitario de la Samaritana de Bogotá debido a un accidente de tránsito en Leticia. Generosamente me dieron el contacto de Arnoldo, su hijo, quien por requisito del seguro médico estaba obligado a acompañar a su padre por tratarse de un adulto mayor. En la primera conversación que sostuvimos, Arnoldo accedió a encontrarse conmigo y a presentarme a su padre, pero debimos esperar a vernos cara a cara para descubrir que ya nos habíamos conocido anteriormente. Al reunirnos, Arnoldo me comentó que, aunque había aceptado que nos viéramos, debió comunicarse con su gente para preguntar por mí. Le informaron, entonces, que yo era aquel blanco rubio y barbado que habían recibido en el año 2004 y que había estado a punto de perder sus mostachos intentando apagar la maloca de Ciro Matapí. Me recordó también porque aquella vez habíamos compartido un largo tiempo cortando enormes árboles para la preparación de una chagra en su comunidad.

Nuestro encuentro en la puerta del hospital fue grato. Nos dimos un fuerte abrazo y nos dirigimos a una cafetería cercana para conversar y tomar un café. Arnoldo me comentó que se estaba alojando en el albergue de Mallamas, ubicado al sur de la ciudad, cerca del hospital San Rafael y de la clínica La Inmaculada, una casona de dos pisos con varias habitaciones acondicionadas con camarotes, un antejardín techado para ver televisión y en condiciones higiénicas aceptables, donde por lo general son hospedados los indígenas que vienen desde sus regiones y a donde esperaban llevar a su padre al salir del hospital. Me contó que Enio, su padre, estaba participando en un concurso de bailes tradicionales organizado por la gobernación, certamen en el que había sido ganador el año anterior y premiado con un viaje a la ciudad de Santa Marta para representar las tradiciones de su comunidad. Esta vez el destino del ganador sería la isla de San Andrés 
en el Caribe colombiano, pero un accidente con una motocicleta, cuando ya se encontraba entre los grupos finalistas, le impidió continuar. Arnoldo argüía que a su padre «le hicieron la vuelta» por llegar a la fase eliminatoria y que el accidente de tránsito había sucedido para sacarlo definitivamente del concurso. Lo anterior no quiere decir que el motociclista que arrolló a Enio estuviera predispuesto para atropellarlo, sino que otra persona, envidiosa por su participación, realizó los rezos correspondientes por medio del chamanismo para perjudicarlo.

En la charla comentó que la fractura de la tibia podía ser tratada por ellos mismos a través de la medicina tradicional, pero que en el accidente su padre también se había golpeado la cabeza y que para ese porrazo no tenían conocimientos; por ello lo llevaron al hospital.

Según el dictamen médico, Enio fue diagnosticado de la siguiente manera: «Paciente de 77 años de edad quien reside en la ciudad de Leticia, presenta accidente de tránsito en calidad de peatón, sufre trauma craneoencefálico y a nivel de miembro inferior derecho, cursando con fractura diafisiaria de tibia y peroné derecho, en plan de ser programado para colocación de clavo endomedular». Es decir, había sufrido una fractura interna de tibia y peroné, el hueso estaba partido en dos y debía ser sometido a una cirugía para corregirlo y ponerle además una placa de platino. En primera instancia la intervención fue un éxito y a los ocho días le realizaron una cirugía plástica para que el platino no quedara expuesto. En la última revisión médica, justo antes de recibir el alta para salir del hospital, se descubrió que el hueso estaba infectado y que era necesario suministrarle antibiótico intravenoso por seis semanas. Esto demoró su salida del hospital, ya que el seguro debía autorizar antes el acompañamiento de una enfermera que suministrara las dosis intravenosas en el hogar de paso de la capital donde pasaría su periodo de convalecencia.

Arnoldo me relató entonces que su padre había llegado inconsciente al hospital San Rafael de Leticia: el golpe en la cabeza lo había dejado desubicado y por los fuertes dolores debió ser sedado para su traslado a Bogotá. La agilidad en los trámites para remitirlo se logró gracias a la intervención de importantes amistades políticas del Amazonas.

Gracias a que el ingreso al hospital en Bogotá se hizo por la sala de urgencias, las autorizaciones de la EPS para su atención y cirugía se despacharon rápidamente.

Cuando lo visité por primera vez en el hospital, Enio se encontraba alojado en una habitación del cuarto piso que compartía con un hombre de los llanos orientales y sin ninguna separación entre las dos camas. El espacio contaba con un baño, una ventana y un televisor. Lo encontré tendido en la cama, vestido con 
una bata delgada de color azul pálido y una pantaloneta y conectado al suero. A pesar de su extrema delgadez por los tres días de ayuno para la cirugía, estaba de buen ánimo y disposición para charlar conmigo. No recordaba absolutamente nada del recorrido entre Leticia y Bogotá, no sabía cómo había llegado al Hospital Universitario de La Samaritana y en muchos momentos de nuestras conversaciones seguía pensando que estaba en Leticia.

La explicación de Enio sobre su accidente fue mucho más allá de la que me había sido dada por su hijo y el dictamen médico. Recomiendo al lector tener especial cuidado en sus prácticas de autoatención ${ }^{4}$ con los lugares y las redes chamánicas, con sus esencias polucionadoras y con sus rezos, así como en sus dos accidentes y las posteriores visitas a los centros de salud.

Creo, entonces, que se hace necesario contextualizar al lector antes de proseguir. Enio me comentó lo difícil que era seguir en el Mirití, pues todos sus hijos habían migrado y ya no estaban con él; entonces, trabajar en la chagra y conseguir alimento era complicado, así como obtener ayuda de la comunidad a través de la minga, ya que él estaba muy mayor y no podía cooperar mucho en la mano de vuelta. También habló sobre su relación en la clínica con los médicos y de cómo ellos preguntaban si sabía curar, lo que él ratificaba como curador indígena. Sin embargo, comentaba que él había «pensado» mal y eso hacía que pudiera estar atravesando por esta situación. Cuando volví a preguntarle por la razón de su calamidad, retrocedió muchos años en el tiempo para explicarme el origen de su mal.

Me explicó que todo había comenzado décadas atrás, cuando estaba de cacería en un salado del río Mirití. Mientras se encontraba en aquel lugar, había caído un rayo que hizo retumbar la selva, y justo en ese momento empezó a sentirse enfermo de la cadera para abajo. El chamán que lo curó en aquel entonces le había informado que su pensamiento se encontraba en la maloca de las dantas y que él, de alguna manera, lo había traído de vuelta. Le dijo, además, que debía sentirse afortunado, pues, de haberse quedado allí, su pechuji sería ahora de la gente danta (illness) $)^{5}$, y que por tanto debía someterse durante un año a un

4 Según Menéndez, autoatención son «las prácticas que la población utiliza a nivel de sujeto y grupo social para diagnosticar, explicar, atender, controlar, aliviar, aguantar, curar, solucionar o prevenir los procesos que afectan su salud en términos reales o imaginarios, sin la intervención central, directa e intencional de curadores profesionales» (Menéndez, 2005, p. 54).

5 Según Kleinman (1980), illness es la experiencia subjetiva que un enfermo tiene sobre su enfermedad; disease es el diagnóstico biomédico sobre la enfermedad y sickness es el desenvolvimiento social que trae la enfermedad. 
régimen alimenticio severo. Le estaba prohibido volver a cazar y comer danta; además, no podía adquirir ninguna esencia de los animales que son considerados peligrosos (autoatención). Su mujer debía cocinarle y servirle su alimento en un recipiente aparte, diferente del que comía toda la familia, para que las esencias polucionadoras no lleguen a él y puedan enfermarlo aún más (sickness). Antes de comenzar la dieta le aplicaban «tinta», que representa el cambio de piel de la persona y la posibilidad de estar keijani (protegido por los espíritus).

A continuación, transcribo apartes de aquel testimonio que Enio Yukuna tuvo a bien compartir conmigo. Su historia comienza con un pequeño altercado con su mujer:

Allá en Mirití [hablando con su mujer]. «Entonces, ¿cómo me voy a rebuscar para comer?». Me dio rabia. «Ah bueno, usted quiere, me voy» —yo dije. Cogí mi escopeta... Ese día como tres horas adentro. Ese día yo bajé y me fui. Y llueva y llueva y nada que paraba. Después yo pensé: «De pronto llegan ahorita detrás de mío, los animales me llevan». Llegué a las tres de la mañana. Yo dije: «Mejor me voy». Yo llegué al ranchito. Cuando llegué a la casa y ella me dijo: «¿Cómo le fue?». Yo no le contesté, me dio como rabia. Ella me dijo: «Usted mismo eso es lo que quiere, ahora aguántese». Ese día me dio fiebre. Me quedé dormido, quedé encalambrado...

Enio tiene claro entonces que su mal se origina aquella tarde en el salado, cuando después de caer un rayo, sintió que su cuerpo se paralizaba de la cintura para abajo.

Sí, todo de aquí pa’bajo. Mi cabeza no la podía aguantar. Ah yo no sé qué me pasó... yo no dije nada. Entonces, yo fui donde el compadre Fermín, ese que está aquí en Leticia. Yo le dije: «Compadre, yo no sé qué me pasó. Yo fui al salado, ahí me cogió rayo. Ahí me llegó la enfermedad, yo siento la maluquera. Todo mi cuerpo duele. ¿Qué será, compadre?». «Ah, ahorita yo voy a mirar». Hizo coca. A las nueve terminó coca. «Ahora sí venga, compadre», me dijo. Sacó coca y mambe, se sentó: «¡Ay, compadre! ¿Sabe qué le pasó a usted? Usted está en peligro», dijo él. «¿Por qué? Yo no hice nada. ¿Por qué yo voy a estar en peligro?». «No, esos animales a los que usted fue a casa de ellos casi llevan todo su cuerpo. De pronto, si usted se hubiera quedado ahí, usted no estaría aquí. Mande curar esa gente que sabe curar. Mañana mismo», dijo él. Yo fui. Al otro día, yo fui saqué coca poquito; entonces yo me fui aquí abajo. Ah, yo le dije a ella [a su mujer]: «Ya me prohibieron comer danta, ya no puedo comer danta. Yo no puedo matar tampoco». «¿Por qué?», dijo ella. «No sé», yo dije. «Yo no puedo contar nada». Hasta ahí, nomás. Entonces, yo vivía enfermo, enfermo, enfermo. Cada nada me daba fiebre, fiebre, fiebre... 
Después yo llegué de abajo acá a Pedrera. Como yo era el viajero en ese tiempo del corregimiento, yo hacía viaje cada nada. Yo llegué, entonces fui donde mi primo. Yo le dije: «Primo, yo me siento malo. Usted que sabe de curación danta ¿será que ellos me hicieron daño?». «Sí, primo», dijo. «A ver, trae, trae ese día ají, ají ahumado». Bueno, traje ají ahumado. Entonces, yo le dije, más temprano, yo le dije [a su mujer]: «Me voy donde mi primo. De pronto me hace curación». Yo pensé lo malo pa'mí. Yo dije: «Me voy». Ella dijo: «Yo voy con usted». «No, señora», yo dije. «Si usted quiere. Si usted no quiere, pues no se va». Pa'qué yo voy a llevar por la fuerza a la gente. «No, yo me voy con usted». Ah, bueno, fuimos con ella. A las seis llegamos allá. Y me dijo: «¿Qué pasó, primo?» Y así me pasó... «Bueno, ahorita yo voy a curar». Sacó ají, lo echó en la cuya y se puso a sentar ahí. Curando, curando, curando. Hasta media noche, más de media noche. «Oiga, primo», dijo así, «usted está bien jodido, bien jodido primo». «¿Por qué?», yo dije. «Porque yo miré los pensamientos, no está aquí», dijo. «Los pensamientos están allá en maloca de danta. Ahí está él [el pensamiento], ahí está, usted tranquilo, ahí jodiendo, ahí con esa gente, pero yo traje su pensamiento, yo traje. Aquí yo lo tengo en la cuya». «¿De verdad, primo?». «Sí», dijo. «Ahora, tiene que guardar dieta, un año sin comer borugo, sin comer venado, sin comer venado colorado, sin comer... ¿cómo es que se llama este?, eh... danta. Mire, póngase un año. Ahí pasa», dijo. Ah, me jodí. «Bueno», yo dije. Después me hizo tinta, me hizo curar esa hoja de la tos. Yo tomé agua caliente, yo vomité. Uy cómo yo boté ese podrido de mi barriga, cómo olía a feo. Bueno, entonces yo me fui. Fuimos allá, ahí yo le dije [a su mujer]: «Ahí está, por usted mismo que me pasa eso así. No es culpa mía».

Como veremos ahora, varios de los brujos a los que se refiere ya no viven en el Mirití ni cerca de La Pedrera, y cuando habla a continuación de su compadre Pepe y de cómo este lo curó, se está remitiendo a una época en la que su pariente aún vivía en el Mirití-Paraná, antes de trasladarse a Villavicencio, como lo narra en su historia. Pepe no es un brujo cualquiera: está considerado como un gran chamán entre los pobladores y es reconocido por tener el poder de sacar la enfermedad. En muchas ocasiones los procesos de curación van acompañados por soplos o por humo y la parafernalia que usa el chamán cambia dependiendo de sus conocimientos y del performance del ritual de sanación. Luego de un proceso curativo, Pepe logra succionar una piedra del cuerpo de Enio. Estos objetos son interpretados comúnmente como flechas que envían los jarechina y que enferman a las personas. Al sacar un objeto intruso del cuerpo del paciente, se exterioriza la enfermedad haciéndola visible y el proceso de sanación es más efectivo; ahí es cuando la subjetividad y el pluralismo médico suceden. 
Entonces yo le dije: «Pepe» [un curador, un chamán], yo le dije: «Pepe, ¿qué será que yo tengo aquí? ¿Qué será?», yo dije. «Este está dormido. Yo me siento como encalambrado». «¿Qué será? Esta noche yo voy a mirar». Él es muy bueno conmigo. Ese Pepe que vive en Villavicencio. Ahorita, nomás, me llamó él, él quiere que yo vaya. «No, yo no quiero ir allá», yo dije. Yo ya fui una vez allá, muy monte. Bueno, este me sacó, sacó, sacó... sacó una piedrita, así, pequeñita. Así pequeñita, piedrita. Sacó chupando. Dijo: «Mire este, tío, este que está jodiendo a usted. Yo voy a botar», dijo. Bueno, botó. Bueno, así yo vivía, vivía, vivía...

Enio fue curado nuevamente durante su viaje al río Apaporis. Algunos de los chamanes de esta zona poseen el poder de visión y también el de sacar la enfermedad. Cuando él cuenta su caso a los brujos, le aseguran que se trata de una curación muy sencilla, pero uno de ellos le pregunta por sus conocimientos chamánicos y de curación. Enio afirma practicar la brujería desde hace tiempo y entonces un nuevo inconveniente se le presenta, pues el dictamen del médico tradicional es que sus mismas habilidades son las causantes de su enfermedad (illness). Entonces, Enio cuenta cómo su tío lo instruyó desde muy pequeño en las prácticas chamánicas y de qué manera esta labor hace parte de él desde tiempo atrás y se cuestiona ante la posibilidad de abandonar el ejercicio místico. En posteriores entrevistas, Enio me narró que, debido a su trabajo con los misioneros en el internado de Mirití, dejó de lado las enseñanzas de su tío para cubrir sus necesidades, pero que estos conocimientos siempre estuvieron latentes en él y esporádicamente los ponía en práctica. Sin embargo, los chamanes del Apaporis le recriminan su falta de seriedad diciéndole que no puede jugar con la brujería, pues esta existe desde la génesis del mundo y que para ejercerla es necesario conocer su cosmogonía. Es entonces cuando Enio recibió la visita en sueños de su difunto tío para completar su adiestramiento en los saberes tradicionales y además recibió el consejo de no dormir temprano ni de permanecer cerca de las mujeres, pues pueden devorar su pensamiento. Es en esta nueva fase de su instrucción cuando Enio aprende los cantos de los bailes, siempre con la tutoría de su tío. Estos saberes le son transmitidos de forma metafísica por medio de las invitaciones de su tío a bailar a su maloca en el más allá. Aunque se aferra a las enseñanzas de su pariente, él desea que otro sabedor interprete esta experiencia onírica para comprender su total significado.

Ellos son macuje, allá de Apaporis. «Ah, bueno», yo dije. «Vamos». Después yo mandé curar a otro brujo de ellos. Yo he pasado mucho de brujos. Por eso es que yo estoy todavía, yo he pasado mano de brujos, muchos, muchos. 
Él me dijo: «Paisano, eso no es nada pa'mí». Yo dije: «A ver, cure, pues». Entonces me sacó ortiga, pushhh. «Mire, este es», dijo. «Había una piedra ahí. Mire, este es, paisano, este es el que te está matando a ti. Mire, yo voy a decir una cosa: ¿usted cura?». «Sí», yo dije. «Ja, usted mismo es el que se está fregando. No juegue con esa brujería de ustedes. Ese no es de ahorita, brujería no es de ahorita, es de antigua. Desde que se originó este mundo. Ahí fue que nació esa brujería. Usted no puede jugar con eso, no juegue con eso. Tiene que pensar antes de hacer eso». «Yo creo», yo dije. Bueno, así ya nos vinimos. Ah, así cómo yo voy a vivir, no me sacó bien; vivía una gota de negro [un hombre negro] ahí en Pedrera. Un negro. Ahí yo dije: «Paisano», yo dije, «yo me siento malo paisano. Este, este, yo estoy muerto, no siento nada». «¿Verdad?», dijo. «Sí, esta noche yo voy a pensar para usted a ver cómo usted piensa». «Bueno». Esa noche mambeamos con él. Hasta media noche. «Venga», dijo mambeando, «usted es muy bueno para brujería. Lo que pasa es que usted mismo daña, por eso es que usted vive así. Pero yo arreglé medio arreglado no más. Después de otro día, «ahí sí yo te arreglo bien, después usted va a andar así como yo», ahí mismo dijo. «Bueno», yo dije. Después me hizo así, bolita. Una bolita así, así bolita, y me dijo: «Ahora mambea. Ahora usted llega a su casa, trae coca, usted fuma cigarrillo, usted se sienta. Siéntese, no se ponga a dormir temprano. Pa' sentar es que uno sabe la cosa, no es así no más que uno duerme, no que este durmiendo a una mujer abrazado, no. Hay que saber». Ahí va llegando a mi cabeza lo que decía el finado, mi tío, eso, la mujer no es buena. Mujeres son malas, malos pensamientos, perdición, ellas comen pensamientos de uno, ahí uno muere. Decía mi tío. Bueno, ahí yo miré que venía bola, así. Allá yo miré que venía bola, así bolita, parece de granadillo, así de grande, bien rojo. Llegó derecho y ahí bajó. Cayó juntó mi pie, ahí se perdió. «¿Qué será eso? ¿Quién será que está jugando conmigo? Bueno, vamos a ver», yo dije.

Entonces, yo me quedé. Ahí yo dormí, yo soñé con el finado, mi tío. Vi que venía, yo vi, cerbatana. Él tenía aquí en el hombro un cosito que tiene colgado. «¿Dónde usted va, tío?», yo dije. «Ya ve», dijo. «Allá está mi casa, allá junto a ustedes. Si usted quiere vaya allá». «¿Será, tío?», yo dije. «Por eso yo le decía a ustedes no duerma temprano, hable conmigo». Ahí sí ya me aconsejó: «Yo te cuento cómo era el nacimiento de este mundo, todo. Eso que le está pasando a usted». «¿Será, tío?». «Bueno, así será, sobrino». Ahí se puso a contarme el cuento; desde aquí es principio de baile, ti, ti, ti hasta terminar; y aquí otro, brujería, yo iba bien. Pero yo mismo me dañé también. Yo iba bien, ya estaba aprendiendo, ya. Ya estaba llegando a mi cabeza; yo cuando me levantaba, yo me quedaba pensado como hacía mi tío. Ahí yo me puse a pensar, allá llegando a mi cabeza ya. Ya está entrando a mi cabeza. Después yo pasé otra vez a Pedrera, ahí yo miré por última vez, el finado Walter. Yo dije: «Paisano, ¿por qué yo sueño así?», yo dije. «Eso 
es que yo vine a preguntar a usted». «¿Cómo es que usted sueña?». «¿Cómo es que yo sueño al finado de mi tío? Ah cada día que yo duermo miro que él viene». Me dijo: «Vamos a bailar, traiga cosas. ¿Qué te decía?». «No», yo dije, «vamos». Entonces yo bailé con él. Y me dijo: «Mire una cosa, me olvidé decirle a usted que no contara a nadie, eso es suyo no más. No puede contar pa' su mujer». "Ah, bueno», dije, «ahora sí me dañé». Yo dije: "Qué le vamos hacer». Así yo viví, yo viví mucho tiempo, así, así. Después ya se fue calmando, calmando mi rodilla, ya se fue curando, bien, no me dolía nada...

Cuando llega a La Pedrera, le pregunta a su paisano por el sentido de sus sueños y este le dice que los saberes que recibe desde otros mundos deben ser solo para él y que al contarle a su mujer puede perder su pensamiento, pues la esencia femenina es polucionadora. El carácter ambivalente de la brujería continúa presente en Enio, que no siente en su cuerpo los dolores de la enfermedad. Más adelante afirma haber recuperado su salud y se atreve incluso a visitar nuevamente la maloca espiritual de los animales (danta) acompañado por su mujer. Pero ella cuestiona sus conocimientos asegurándole que son causa de su enfermedad y además lo desafía exigiéndole que le cure un mal estomacal. Enio no sabe cómo afrontar este reto, pues su mujer es huitota de la Chorrera, gente lejana, y no tiene conocimientos para curarla. Para salir del aprieto y no dejarse amilanar, la envía a traer agua y le promete que con su oración la curará. Así, declara ante su mujer que la causa de su enfermedad no es otra que las mismas dantas, pues ella tomó su «guarapo» (el agua del salado).

Entonces yo le dije a ella: «Ahora sí me voy al salado. Yo me voy para allá... yo mato una danta para comer». «Ah, bueno», dijo. Yo cogí remo como a las dos y déle para abajo y déle para abajo, remo, como tres horas remo. Yo entré a salado y como entró danta a salado, mucho rastro. Yo le dije a ella: «Así», yo miré a mi tío. «Así», me dijo él, y él me regañó, por culpa mío, no es culpa de nadie. Ella me dijo: «Ya usted se dañó, usted no va a estar bien con eso que usted sabe, así usted va a estar por un tiempo». «Bueno», yo dije, así yo me quedé, después yo soñé. Después ella me dijo: «No cure», tanto que ella me dijo «no cure». Ya que ella dijo «no cure», cómo yo voy a negar, cómo yo voy a negar a mi dios, él sabe que yo sé, cómo yo le voy a decir que no sé nada, si él sabe que yo sé brujería de él. «Ah, bueno», dijo. «Ya que usted quedó así, ¿qué será que me pasó en Pedrera? Yo no puedo estirar mi barriga, ya que usted dice que usted sabe, pues cure». Ahí ella me sacó ya en la cara: «Ya que usted dice que sabe, ahora cure», me dijo. «Acaso yo te voy a curar», yo dije. «Así es que uno no puede, como decir... pa'otras formas». Esa misma curación es solo una línea, solo una parte, nomás, cómo voy hacer curación, es la misma curación, mire, aquí va una rama, aquí va otra rama, aquí usted coge 
rama... hasta terminar. Dónde voy a hacer trabajo ese», le dije. «Cure» [le dijo la mujer]. «Vaya a traer agua», yo dije, así, jugando, «vaya a traer agua», así yo dije. «Ahí no hay nada», dije. «Sí, sí, lo que le dañó a usted fue ese animal, ese danta, aquí de salado, aquí de Tonina [nombre del salado], que usted tomaba agua de aquí, de Tonina». Es que uno no aprende así, nomás, para aprender, aprender, aquí la cosa tiene que trasnochar...

Hace entonces un gran salto en su narración para regresar hasta Leticia — aunque en su narración dice que es La Pedrera_- en donde afirma haber visto cómo el cemento se asemejaba al agua. Acompañado aún por su mujer en aquel lugar, empieza a sentirse mal. No queda del todo claro si el malestar que padece en ese momento le suscita las sensaciones anteriores o si se trata de una percepción de las calles de la capital del Amazonas, pero cada uno decide tomar su propio camino para recorrer la ciudad, y ya solo, mientras cruza una avenida, es atropellado por una motocicleta. En su relato no sufre mayores dolores por lo ocurrido: se pone de pie y es llevado hasta el hospital de Leticia donde le aplican alcohol («Me bañaron en alcohol») y se reencuentra con su mujer en casa.

Llegamos a Pedrera, salimos, andamos en Pedrera pueblito, pueblo. Entonces yo le dije a ella: «¿Cómo iba a ser?». Yo miraba así cementado, pura agua. Arena, pura agua. Yo pisaba así, era arena. «Bueno, entonces, ¿cómo yo voy a hacer?». Entonces ella me hacía cruzar al otro lado la calle. «Yo no estoy bien», yo le dije. «Vamos a ver. Me voy por aquí. Usted se va por ahí». Yo llegué, yo vi mucho tarro ahí botado de cerveza: «Yo voy a llevar tarro pa’yo vender». Yo crucé así, yo iba a llegar allá, ahí llegó una moto, atrás venía otra moto vieja, atrás venía otra moto, de una vez llegó me cogió, aquí, me cogió de aquí, yo me caí. Llegó el policía y dijo: «¿Qué pasó?». Yo dije: «No pasó nada. Lo que pasa es que esa moto me estrelló, no pasó nada, no pasó nada, solo aquí que me cogió poquito», yo dije. Bueno, entonces el policía dijo para este motocarro: «Lleve a él de urgencias ahorita mismo». Bueno, me llevó a dejar allá en el hospital, como a esta hora será. Yo esperé a donde ella se fue. Nada, bueno yo me fui a doctor; bueno me dieron todo de este suero, me dieron remedio, me bañaron en alcohol. Ya tarde eran como la 5:30. Yo dije al motocarrito ese: «Vaya y me deja». Bueno, yo llegué, ahí estaba ella, yo llegué y le dije: «¿Qué usted hace?». No me contestó nada. «Yo no estoy haciendo nada, ¿para qué es que usted quiere saber qué yo hago? Así como usted dice que hace y yo no digo qué usted hace».

La mayoría de su testimonio está impregnado de un constante cuestionamiento a su mujer por ser la causante de todos sus males: ella lo manda a cazar y es cuando él enferma; él quiere retirarse al ancianato y ella desea quedarse donde están; ella además le recrimina que realice brujería y pone en duda sus saberes. 
Sin embargo, es reiterativa la sensación de angustia por perderla y la posibilidad de que ella se vaya con otro hombre. Incluso al final del relato Enio se pregunta si su convalecencia en Bogotá puede hacer que ella lo abandone definitivamente. A pesar de las quejas sobre su mujer, ella lo visita en el hospital de Leticia para alimentarlo, aunque a él no le guste la comida que le trae, y en esa ocasión, seguramente por los efectos de los sedantes, Enio la ve llegar con la cara negra. En Bogotá también recibirá su visita, pero esta vez en sueños, lo que revela la necesidad del hombre por los cuidados femeninos.

Ya, ya, sí, ya, ahorita, ahorita como diez años será. Entonces, yo la llamé y le dije: «Venga, yo le voy a decir una cosa a usted: ¿será que le gusta o no le gusta?». Ella me dijo: «¿Para qué? A mí nadie me aconseja, yo ya estoy vieja». Y yo le dije: «No, yo no te voy a aconsejar, yo te voy a decir una cosa que es verdad. ¿Por qué usted no me hace caso? ¿Cuánto tiempo usted ha vivido conmigo? ¿Cuánto tiempo trabajando, haciendo chagras, sembrando, arrancando yuca, rallando, colando, sacando almidón, sacando leña, haciendo fariña? ¿Cuánta plata usted hizo conmigo? Si quiere acuérdese». Yo dije: «Aquí a mañana usted se consigue un hombre, se va a conseguir un hombre, va a conseguir». Yo estoy muy viejo. Antes de que me pasara esta cosa, yo le dije a ella: «Ahora que me pasó esto, ¿cómo es que usted piensa?». Yo estoy pensando, ya que estamos viviendo mucho tiempo, llevo muchos años con ella, más de trece años. Ella dice que yo no le sirvo al trabajo. Mire, hicimos chagra, hicimos fariña, hicimos casabe, hicimos almidón, hicimos fariña, i¿qué más?! ¿Cómo dice que yo no hice nada? «Agua que yo traigo. Ya que usted dice que no sirvo». Ella dice que hay mucho hombre, pues hay muchas mujeres también. Ya yo le dije: «Usted cree que yo no estoy haciendo nada, esto que usted está trabajando, haciendo chagras, fariña y vende para usted misma y la plata mía no toque». "Yo veré qué yo hago. No», dijo [citando a su hijo Nelson]: «Papá, usted mire ahora que vamos a ser fariña yo voy a decir a mi mamá que mande para mi papá fariña». «No, mijo», yo dije. «Mire, le voy a decir una cosa, dígale a su mamá que yo no necesito ahorita nada de su mamá, ni fariña ni nada de casabe. Yo le dije a ella bien ese día antes de que me pasara algo que fuera a la chagra y que me hiciera poquito pa'llevar, casabito, caguanita para llevar».

En sus experiencias oníricas, Enio recibe también la visita de sus nietos, que le traen de comer hojas de assai, las cuales rechaza. Esto le recuerda la comida del hombre blanco que le fue ofrecida en su viaje a Santa Marta, una ensalada que para él son puras yerbas para alimentar a los animales y aprovecha para desahogarse sobre los insípidos consomés del hospital y reafirma que la verdadera comida es la de su región, lo que ratifica la conformación de humanos verdaderos, su pechují e identidad. 
Dentro de su itinerario terapéutico, se muestra cómo su estado de inconciencia le impide tomar decisiones respecto de su salud. Son sus familiares quienes deben autorizar los traslados y procedimientos y su posterior remisión a Bogotá. Los costos de la operación, los exámenes médicos y el alojamiento en el albergue fueron asumidos por Mallamas (EPSI), pero su regreso a Leticia debió ser cubierto por sus familiares, quienes en repetidas ocasiones enviaron dinero para que Enio contara con algunos enseres adicionales. Al despertar de la anestesia se descubre inmovilizado, conectado al suero, cubierto de sangre y sin saber muy bien cómo hacer sus necesidades fisiológicas. Pero a pesar de su durísima estadía en Bogotá, se declara una y otra vez como gran brujo ante todos los que bien quieran escucharlo: médicos, enfermeras y parientes, y no deja de mencionar a sus antecesores para demostrar que no es cualquier persona, pues viene de un linaje de renombrados brujos. El traslado al hospital lo lleva a experimentar un momento de liminalidad, en donde en muchas ocasiones desconoce el lugar en el que se encuentra, qué le sucede y los procedimientos para su curación.

Yo sufrí mucho tres días, yo aguanté hambre, yo no comí nada, ni agua. En tres días yo no comí nada, antes de operarme. Después de eso me dijo [el médico]: «Usted ya comió algo, ahora no puede ni tomar agua». «Bueno», yo dije. Entonces yo dije: «Doctor, usted es un doctor, yo soy otro, yo soy malo... yo soy malo, yo soy así. Yo no soy cualquiera. Mi abuelo no era cualquiera, mi abuelo era un brujo grande, volvía tigre, volvía culebra, mataba entre ellos mismos, ¿cómo no voy hacer?, lo mío es lo mismo».

El accidente de tránsito es el último episodio en ser narrado, el último capítulo en su historia de dolores y malestares, los cuales comenzaron muchos años atrás, cuando visitó el salado y las dantas querían apoderarse de su pensamiento, y que se agudizaron por sus malas prácticas en brujería, pero su triunfo en un concurso de bailes típicos también jugó un papel importantísimo en sus desventuras, pues la envidia se convierte en el móvil de las maldiciones que resultan en el accidente final.

Yo dije: «Este que me pasó de camino, yo no sé dónde fue qué me pasó ahí camino al ancianato, en el matadero, ahí fue donde ella me encontró todo lleno de tierra». Ella me dijo: «¿Qué le pasó?». «Yo no sé qué me pasó, qué voy yo a saber, no me pregunte. Eso que me pasó, ahora será que yo me voy», yo dije. «¿Cuánto tiempo?». «No sé, ¿cómo yo voy a saber?, ellos que saben bien». Ese mismo día me llevaba por allá, yo estaría sanando ya ahorita, ese no es nada [ríe]. No es nada, curación a los tres días yo estoy curado; muchas veces yo he curado esa zafadura, que se parta así a gente con esas hierbas 
rojas, uno hace calentar tres veces. Mire, el otro día se partió zanca de uno de allá del internado, partió de aquí, de una vez le salió sangre; con tronco y piola, ahí trozó el hueso, y ahí quedó. Nadie lo curó a él y como sano y despegó otra vez. Mire, otro que se partió del Caquetá, Aníbal, que iba de cacería, que pisó malo y se zafó el pie, quedó chuequito y así anda.

\section{EL PENSAMIENTO PECHUJÍ, LA SALUD Y ENFERMEDAD}

Para entender de una mejor manera el concepto de salud y enfermedad de los pueblos indígenas del Mirití Paraná y su relación con el relato de Enio Yukuna, es necesario comprender el concepto de pechují — «pensamiento»- en lengua kamejeya (yukuna). Según el diccionario del Instituto Lingüístico de Verano (Schauer, Schauer, Yukuna y Yukuna, 2005, p. 131), pechují se puede definir como «alma», «espíritu», pero esta explicación no concuerda con el testimonio de varios indígenas a los cuales he tenido la oportunidad de entrevistar al respecto y quienes afirman que, en efecto, pechuji se refiere al pensamiento, mientras que «alma» podría ser pechujimi o pechu y «espíritu» ripechu. Camilo Robayo asevera que ripechu es «idea», «emoción», y es un sustantivo, no un verbo, por lo tanto, es moldeable, intercambiable si se quiere, y se atribuye a los objetos, a los temperamentos y a los órganos de las personas ${ }^{6}$.

Los animales, plantas, piedras, agua y viento son vistos también como seres que tienen pechují, por lo cual los chamanes deben saber las curaciones o conjuros rimana $a^{7}$ para hacer en su brujería lawichu. Si el pensamiento es asimilable a las «camisas» que pueden usar los chamanes y que poseen los demás seres, daría un espacio al animismo, pues querría decir entonces que todos los animales poseen alma, la cual es adquirible e intercambiable en la cosmopolítica por los especialistas, quienes son los únicos que pueden ver y hablar con los «dueños» de la naturaleza, causando bienestar o malestar en las personas.

6 Según Robayo, «la extensión de propiedades del significado de ripechu “idea/emoción” genera los sentidos de objeto, vehículo, personificación y posesión que permiten atravesar el espacio, incorporarse a entidades y actuar sobre ellas, tal como se atribuye a la brujería/chamanismo [...]. El análisis de las distintas expresiones del vocabulario de los modos de ser de las personas (emociones, actitudes, carácter, roles) mostrará que ripechu se origina en la experiencia de ideas, intuiciones, afectos, intenciones y representaciones» (Robayo, 2007, p. 122).

7 «Cuando definen la palabra (ri)-maná o manaji (forma general), los kamejeya entrevistados se refieren a los conjuros u oraciones, fundamento de actividades chamanísticas como la curación de objetos o la preparación de eventos rituales colectivos» (Robayo, 2007, p. 124). 
En las sociedades amazónicas está ampliamente reportado el hecho de que los animales tienen camisas o «ropa» (na'mácana en lengua kamejeya) ${ }^{8}$ y que los chamanes pueden hacer uso de ella y de esta manera transformarse y viajar espiritualmente por el mundo en forma de animales. Al ser intercambiable el pensamiento pechují, es posible conseguir alimento, pero al mismo tiempo puede ser perjudicial, ya que las personas que no han recibido la prevención y curación necesarias pueden adquirir el pechují de algún animal, planta o lugar, volviéndose presas de otros chamanes o «dueños» de la naturaleza hasta llegar a enfermar, y en ocasiones, a morir.

A través de la interpretación del mundo se puede ver una simbología común en los indígenas del río Mirití-Paraná y sus cosmologías. Hablo de estas últimas en plural, porque cada etnia cuenta con una concepción cosmológica propia sobre los orígenes de las cosas y de su gente; no obstante, en general se aprecia que los indígenas tienen un esquema de pensamiento común, basado en la interacción con el mundo que los rodea. Esto hace que sus pobladores posean un significado de enfermedad propio que difiere del occidental en varias cuestiones: toda dolencia es creada por un comportamiento social dado y no por el azar. También pueden existir casos en donde un individuo se enferma a causa de otro miembro de su comunidad o de comunidades vecinas: esto se explica ya que el orden de estas sociedades está regido por el camino de curación del tiempo, que dependiendo de cada época tiene prevenciones especiales, como bailes, dietas, yuruparí y otros rituales, que a su vez exigen a los comuneros el cumplimiento de las normas establecidas por el chamán, y si alguien incumple alguna de estas imposiciones puede ser el causante de una afección. Por ejemplo, si Pedro come o'jo $o^{9}$, que le había sido prohibido por el chamán, puede enfermarse y también enfermar a su hermano, a su madre, a su primo o a su paisano.

\section{EL TERRITORIO}

El chamanismo indígena se caracteriza por la habilidad para manejar el contacto con los seres espirituales que existen en la naturaleza. Las enfermedades, desde el punto de vista émico, son causadas por los diferentes dueños de este y otros

8 Un ejemplo de esto está dado por Arhem, Cayón, Angulo y García (2004) para los makuna, Chaumeil (1998) para los yagua, Viveiros de Castro (2007) para los xinguanos, Correa (1996) para los taiwano, Karadimas (2011) para los miraña y Langdon (2014) para los siona, entre muchos otros.

9 O’jo, jó ojo: alimento prohibido por dieta (Schauer, Schauer, Yukuna y Yukuna, 2005, p. 124). 
mundos que bajan, suben y rondan en nuestro plano para causar mal, como ha sido relatado por Enio Yukuna. Para evitar esto, es necesario que el chamán entre en conversación con los espíritus que habitan en ellos y vaya con su pensamiento hasta las malocas donde se encuentran. Estas se ubican en los sitios sagrados ${ }^{10} \mathrm{y}$ cada ser mítico vive en una maloca con toda su gente y sus implementos, al igual que el chamán. Allí, los brujos hacen un pagamento con coca, tabaco de oler y tabaco de fumar para que los espíritus permanezcan tranquilos en su maloca y no causen enfermedad a los hombres.

El universo, la naturaleza y el hombre se encuentran dentro de un mismo flujo de esencias que son complementarias, masculinas y femeninas. El manejo de estas esencias está sujeto a la reproducción biológica y social ${ }^{11}$, por tanto, cuando se caza un animal, la «camisa» que este posee es adquirida por los individuos que la consumen. Para el caso de los yukuna-matapí, los jarechina son los «dueños» espirituales de los animales de cacería, viven en malocas al igual que las personas y es con ellos con quienes se debe negociar cuando se sale en busca de carne de monte. Se dice que las malocas de los jarechina están ubicadas en el primer mundo inferior, el «pensamiento» o alma de los animales, y en este espacio son iguales a nosotros los humanos, pero al salir por la floresta se visten con sus «camisas» y son vistos entonces como dantas, cerrillos, puercos, venados, etc. Y si en algún momento se realiza la cacería sin permiso del jarechina, este podrá enfermar a algún miembro de la maloca e incluso causarle la muerte si la caza continúa en un solo lugar. Además, su «pensamiento» podrá convertirse en parte de la «gente» de la maloca del jarechina.

Las etnias de esta zona hablan que los animales, en algún momento anterior al nuestro, fueron humanos que, por diversas situaciones narradas en los mitos, se convirtieron en gente-animal, ya que el primer mundo inferior, donde se encuentran las malocas de los jarechina, hace referencia a las épocas anteriores.

10 Para Van der Hammen (1987), es necesario tener en cuenta la maloca dentro del manejo del territorio, «para entender el uso del medio ambiente por los yukuna es necesario tener presente la manera de concebir por lo menos cuatro elementos básicos: la maloca, el territorio, el paisaje y sus dueños espirituales y el ciclo anual, los cuales actúan de manera interdependiente mediante acciones del chamán» (p. 89). Viveiros de Castro (2017) habla en su perspectivismo amerindio de que todos los seres con alma, incluyendo a los animales, se perciben a sí mismos como humanos y sus vidas están caracterizadas por malocas, chagras, etcétera. El modo en el cual una especie observa a otra depende del cuerpo del observador. Reichel-Dolmatoff (1968) muestra cómo, para los desana, también los dueños del monte viven en malocas.

11 Mahecha (2004) con los makuna; Hildebrand (1983) con los tanimuka, Van der Hammen (1987) con los yucuna, Reichel Dolmatoff (1968) con los desana, Reichel Dussan (1987) con los yucuna tanimuka, Franky (2004) con los tanimuka, Robayo (2007) con los yucuna. 
Entonces, cuando se dice que las sustancias consumidas por los humanos se deben curar $^{12}$ significa que la persona al alimentarse adquiere en su cuerpo la «camisa» del animal, y por tanto es susceptible a la predación por los chamanes que andan recorriendo el territorio con su «pensamiento», enfermándolo o causándole la muerte, lo que obliga a que estos rezos y pagos con los jarechinas no se puedan obviar. La negociación del chamán es una compra o intercambio con coca y tabaco, lo que evita que los jarechinas ataquen a las personas por perder a una persona-animal de su propia maloca. Adiferencia de planteamientos anteriores, lo narrado en el río dice que estas personas-animales, al igual que la gente, se reproducen entre ellos, creando nuevos «humanos» para su maloca; sin embargo, la intervención directa del chamán es necesaria para la reproducción en las malocas de los jarechinas.

Hildebrand (1983) señala que para la ufaina (tanimuka) el «pensamiento» es la energía vital de cada uno y de todos los seres que existen en la naturaleza. Estas energías se encuentran distribuidas en tres espacios: el de arriba es denominado wehea (mundo superior, cielo, masculino) ${ }^{13}$, el de abajo, la tierra, es ñamato (mundo subterráneo, tierra, femenino) ${ }^{14}$, el plano intermedio es aquel en donde estas dos energías confluyen, ñamato boikó, y en él se da la vida. Su modelo se basa en el de Reichel Dolmatoff, en el cual el sol es la energía seminal que lo fertiliza todo al entrar en contacto con la tierra - ñamatu—. Entre todos los niveles, tanto horizontales como verticales, hay flujos de energía constante que

12 Mahecha nos cuenta que entre los makuna hay varios procedimientos cotidianos para la preparación de la comida, ya que es necesario despojar a un animal de sustancias impuras, pues al ser ingeridas los cuerpos de las personas se impregnarían de ellas. También podrán ser lastimados con ciertos atributos físicos del animal. Nos habla de que la mayoría de enfermedades de origen animal y vegetal son atribuidas al incumplimiento de las dietas, las normas para manejar las áreas de pesca, cacería o recolección de frutos y materias primas, o a la actuación perversa de un pensador (Mahecha, 2004, p. 119). Para la sustancialidad en la gente de centro ver Echeverri (2012), entre los tanimuka, Franky (2004), para los makuna, Arhem y otros (2004).

13 Según von Hildebrand (1987), para los ufaina wehea se compone por seis espacios diferentes: imararimakârâ wi'ia, «la maloca de los cuatro seres vivientes»; aya wi'ia, «la maloca del sol», el mundo de la música; opireko wi 'ia, «la maloca de los espíritus»; wayúrina wi’ia, «la maloca de wayúrina», el mundo de los gallinazos; kari wi'ia, «uno de los dueños de la semilla cultivada»; makuémari, «el dueño de la cacería».

14 Namatu se compone de seis espacios inferiores: ñamato neiko «mundo/tierra negra», ñamato waruriko «mundo/tierra amarilla», ñamato boborico «mundo/tierra naranja», ñamato yururiko «mundo tierra negro y amarillo» ñamato ooriko «mundo/tierra roja». Son seis espacios o mundos. Los yukuna-matapi, por su lado, cuentan con cuatro superiores y cuatro inferiores (Hildebrand, 1983). 
deben estar en equilibrio para que no exista enfermedad. Este sistema, donde hay una constante cantidad de energías, se puede debatir, ya que las malocas de los jarechina están en el mundo inferior y es posible conseguir gente-animal a través de los pagos con coca y tabaco. Asimismo, las camisas de animales con las que se visten para salir por este mundo se pueden adquirir, pero no pueden ser restituidas; solo cuando el jarechina descubre que faltan demasiadas «personas» en su maloca decide reestablecer su «personal», adquiriendo el alma o «pensamiento» de alguno de los individuos que se encuentran cazando en este plano para que así vaya a vivir en su maloca, pues ellos se reproducen de la misma forma que las personas de este mundo; por lo tanto, no se puede hablar de un restablecimiento de energías, sino de un pago por las «camisas» que salen a este mundo.

En el plano en el cual nos encontramos hay una gran cantidad de lugares sagrados que comienzan en la «cepa» (semilla) del mundo, que es la desembocadura del río Amazonas en el océano Atlántico, y siguen su curso en dirección oriente-occidente hasta el raudal de Araracuara, en el río Caquetá, pasando por el río Mirití y bajando por el río Apaporis. Es el recorrido denominado como lawichu, que es el camino del pensamiento, enfermedad o curación, y por él fluyen las esencias que fertilizan el mundo y causan la enfermedad en las personas. Es recorriendo este curso y dando pagamento a los diferentes dueños espirituales como puede restablecerse el equilibrio.

En este esquema se muestran los cuatro mundos del cosmos: en la parte superior se encuentran los cuatro seres poderosos Kaipulakena (Kaypu, Mayakaypu, Kayapichi y Wajmachi), quienes nacieron para proteger a la gente de ejawua - nuestro mundo-, compraron la maloca, la noche y tumbaron el árbol-río, creando los cauces actuales. Además, dieron forma a la geografía del territorio en sus travesías y en sus viajes entre las malocas daban protección a los humanos contra los seres mitológicos que querían acabar con ellos. El menor, Lamuchí, al desobedecer varios dictámenes de los dueños de estos elementos, dio origen a los trabajos comunitarios y a la organización social. El segundo mundo le pertenece a Jeechú, quien es al mismo tiempo el sol y padre de la luna y de algunos árboles silvestres como la bombona, el asai, y diferentes animales entre los que se encuentran el colibrí y el chichico; además, es quien domina la fenología del bosque. El tercero es el mundo de Jiñá —el diablo—, a donde llegan los pechuji de los muertos, que al arribar toman el achiote ubicado junto a su maloca, maquillándose y cambiando de nombre para ingresar a su interior. Allí también se encuentra el rayo usado por los chamanes para probar el poder de los demás, causando enfermedad y muerte en otras comunidades, especialmente durante 
el tiempo ritual. El último de los mundos es el de los wayuna — gallinazos-, quienes ven a la gente como sardinas y bajan a barbasquear a nuestro mundo para llevar a su maloca lo recolectado y entregárselo a su mujer para que la cocine y alimente a sus hijos.

\section{Figura 2. Mapa cosmológico de la etnia yukuna}

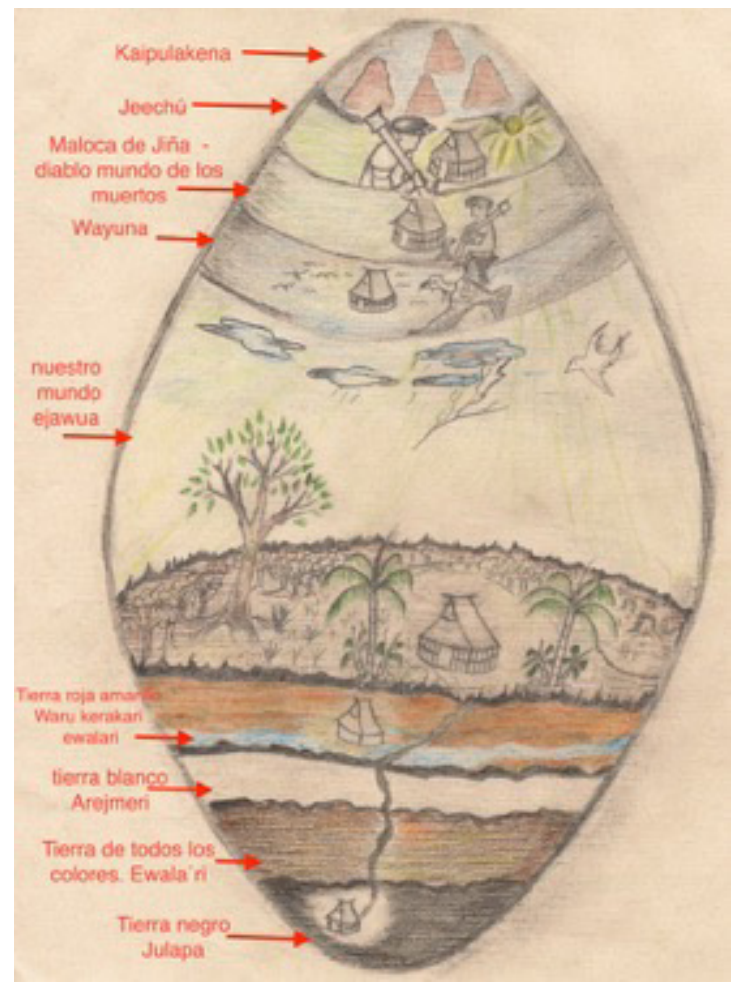

Autor: Pichawata Yukuna (2018).

Los mundos inferiores corresponden a épocas anteriores. El primero, de abajo hacia arriba, es tierra negra Waru Ñamatu Julapa, «la cepa del mundo», lugar donde habita Yuruparí y tiene su maloca; allí viajan los chamanes a través de su pechují a convocarlo para que aparezca en nuestra tierra con todos sus implementos. El siguiente es el nivel donde se mezclan todas las tierras Waru Ñamatu Ewalari y es usado por los chamanes para realizar curaciones del mundo. El tercer espacio es tierra blanca Waru Namatu Arejmeri, que se asemeja a las cenizas y es utilizado para hacer Lawichu; en el mundo justo inferior al nuestro, tierra roja 
amarilla Waru Namatu Kerakari, existe el río que no contiene enfermedad, que cayó cuando los Kaipulakeno buscaban el agua y fueron engañados por su tía Namatu y también es el mundo donde los jarechinas tienen sus malocas.

Por último, entre los mundos cósmicos y los subterráneos está el nuestro, donde confluyen las esencias de los mundos superiores, que son masculinas, y las esencias de los mundos inferiores, que son femeninas. Allí se da la vida ejawua - y por tanto la construcción de las malocas y las chagras, conviviendo con la selva, la lluvia y los rayos que viajan desde los mundos de arriba para dar centellas ante nuestros ojos. En este plano también se recorre el camino de pensamiento: lawichú. Los puntos más importantes son los raudales, remansos, lagos, cananguchales y salados (umawari), ya que allí existe la mayor cantidad de esencias y minerales del medio circundante con su pechuji. Se habla que es donde quedan las malocas de los jarechinas, y su gente sale a este mundo a «rebuscar» cacería y tomar su «guarapo». Cuando los chamanes hacen su recorrido espiritual e invitan a mambear a los pajinamí de la subtierra, están evitando las enfermedades en este plano, ya que pagan por sus «camisas» y de este modo ellos no vienen a cazar y llevar el pensamiento de las personas a su maloca.

Las personas de las diferentes culturas y la naturaleza se consideran humanos, pero cada cultura es, según su etnocentrismo, la única con personas verdaderas. De esta forma se vuelve a la dicotomía de lo natural y lo realmente humano. Hay un aporte adicional que se podría llamar la transgresión, mediante la cual las personas humanas pierden este don de «lo humano» y se convierten en animales, momentánea o permanentemente. Pero igualmente existe la posibilidad de no perder el carácter humano, sino que la persona adquiere la esencia de un animal para ampliar su poder, teniendo un alma, «pensamiento» o esencia, de los grandes animales de caza como el jaguar. Es lo que Viveiros de Castro llama «muchos espíritus en un cuerpo».

Estos hechos son recurrentes en varias sociedades de la Amazonia, y en el caso de las comunidades del río Mirití-Paraná, se dan de la misma manera. Todos los lugares que hay en el territorio tienen un «dueño» espiritual jarechina, con el cual el «maloquero» (chamán) debe negociar. Por ejemplo, si alguien decide ir a cazar a un salado, tiene que hablar con él para que le haga una protección, así podrá ir sin que le suceda nada. Después de eso, si tiene éxito y caza un animal, este debe ser «curado» también, al igual que las personas que se van a alimentar de él para evitar cualquier tipo de enfermedad.

Las prácticas de prevención y cura van relacionadas con el manejo de las sustancias y el cuerpo. Como se ha expuesto en varios trabajos, las esencias de 
los animales se transfieren a la persona que los consume; de esta manera, si una persona no ha sido «curada» y se alimenta de ellos, quedará expuesta como si fuera ese animal, logrando que otros chamanes — hombres jaguar - o espíritus de la selva lo vean en «forma animal» y lo cacen, haciendo que este individuo enferme o muera.

$\mathrm{Al}$ interior del ciclo anual es necesario realizar diferentes rituales y con ellos cumplir las reglas establecidas, más que todo en cuestiones relacionadas con la comida y la sexualidad, que son los flujos de sustancias corporales: semen, sangre (menstruación), esencias (alimentos). Es a través de estas restricciones como se moldean el cuerpo y la salud, del mismo modo que la reproducción social y cultural del grupo.

La maloca es un elemento principal en todo el manejo de la salud, que se considera una construcción social — cultural — y no solo como la sintomatología sobre un individuo ${ }^{15}$. Esta estructura tiene un simbolismo realmente amplio y cada espacio representa algo distinto y asociado: los estantillos (postes de soporte) son los cuatro seres míticos que crearon el mundo y sostienen la cumbrera, que a su vez sirve de reloj y calendario solar, ya que, dependiendo de por donde pasen los rayos del sol, se sabe con exactitud qué época es. Adicionalmente, su estructura y forma de albergar a las personas evidencia las jerarquías comunitarias - maloqueros, cantores, secretario, casados, solteros y solteras, etcétera. También existe lo que se denomina como lawichú («brujería-camino de pensamiento»), representado por las puertas ubicadas en sentido oriente-occidente, los estantillos secundarios y el cerco, que simbolizan a su vez los diferentes lugares en el territorio, los dueños espirituales - jarechina - y otras etnias. Asimismo, las diferentes formas en las que se tejen las hojas de puy, que es la palma con la que se hace el techo y que a su vez simboliza los mundos superiores (masculinos/wehea), y el tablón que hay en suelo y que representa los mundos subterráneos (femeninos/ñamatu) y su confluencia, donde se crean y recrean la vida y su cultura.

Este espacio, al igual que otros lugares, tiene sus restricciones y tabúes. Por ejemplo, las mujeres en menstruación deben permanecer afuera, y en caso de entrar, si el maloquero lo permite, los hombres de la maloca deben primero sacar toda su parafernalia chamánica: collares de dientes de tigre, plumaje, macana y multitud de enseres. Si esto no se lleva a cabo, el calor de la mujer deja sin

15 Para saber más sobre malocas, ver Karadimas (2012), Cayon (2002), Arhem y otros (2004), Pineda (2014), Echeverri y Roman-Jitdutjaaño (2011), Hildebrand (1983), Van der Hammen (1987), Correa (1996), entre otros. 
«pensamiento» estos utensilios, privando a la comunidad de protecciones y abandonándola a la suerte de las enfermedades de los jarechinas, como de otros chamanes que quieran causarle daño.

En el interior de la maloca también reposan los restos de los difuntos, lo que la convierte a su vez en cementerio. De esta manera, no solo representa a los primeros seres míticos, el territorio o la organización social, sino también la filiación al territorio a través de sus ancestros. Es un lugar de culto donde vida y muerte se encuentran.

\section{CONCLUSIÓN}

Estas letras son un intento por realizar un recorrido a través de la cosmología indígena de las comunidades del noroeste amazónico, donde la comprensión de la enfermedad trasciende el acontecer de un accidente de tránsito y el porqué de un suceso va más allá de los elementos probatorios, muchas veces haciendo necesario viajar en el tiempo - tres décadas, en este caso- para encontrar el origen del padecimiento.

En el itinerario de Enio se evidencia el papel que las redes sociales jugaron durante su padecimiento; su mujer es una figura central durante toda su narrativa, el acompañamiento de sus hijos es fundamental y muchos de los chamanes que lo curan forman parte de su familia. Son estas redes sociales también las que intervienen de manera crucial al momento de la remisión, pues es gracias a las influencias de las amistades políticas de la familia que sus procedimientos se dan de manera ágil y efectiva. Las migraciones también son esenciales para comprender la razón por la cual Enio abandona su casa, su chagra y su comunidad, para ir a vivir en lugares donde pone en peligro su integridad.

Se puede ver cómo las enfermedades que padecen los individuos de estas poblaciones tienen una relación con su cosmogonía y cosmología, y aunque sean tratados en hospitales y centros de salud, sus propios modelos explicativos sobre su padecimiento son muy extensos y por tanto se hace necesaria la intervención de redes de chamanes especializados para explicar aquello que los aqueja, pues sus caminos de curación trascienden las explicaciones físicas del padecimiento.

Los procesos de pluralismo médico están claramente reflejados en el itinerario terapéutico de Enio, donde chamanes con diferentes saberes y cosmogonías actúan para resolver sus problemas, aunque todos ellos tienen un sentido común sobre los causantes de la enfermedad, que son bien comprendidos por el paciente, y sus 
métodos y causas cambian a lo largo de la narrativa. Los agentes polucionadores, como dice Douglas (1966), son un factor pertinente para analizar las causas que los indígenas atribuyen a sus males: las dietas, la relación con su mujer, las sustancias y los lugares cargados de pechují se deben tener en cuenta dentro del comportamiento de una persona verdadera, pues estos se convierten en elementos cruciales para mejorar y superar el padecimiento, al igual que exponer los cuerpos de los individuos frente a espacios y la práctica de rituales que causan y previenen las enfermedades.

La cosmopolítica es crucial para entender el relacionamiento indígena con el medio y cómo este puede causar agresiones físicas a las personas, convirtiéndose en el modelo de diálogo entre humanos y no humanos, lo que permite entender qué le sucede al enfermo y cómo sanarlo. Cuando el hijo de Enio narra que el accidente de su padre es consecuencia de la envidia o que el hacer brujería y pensar mal para otros son móviles de su padecimiento, deja claro que la enfermedad trasciende lo físico para entrar en un plano más amplio, aunque fue solo al poner en conversación estos saberes con el biomédico, es decir, al abrir el camino de la intermedicalidad, que el paciente logró salir de su percance y solucionar en gran medida lo que le sucedía. Queda la incertidumbre de saber qué pasó a su regreso a Leticia y así conocer qué curaciones adicionales realizó para resolver y prevenir este largo camino de curaciones y padecimientos. Como bien dice Enio: «Yo he pasado mucho de brujos. Por eso es que yo estoy todavía».

Es importante ver cómo los sistemas médicos se pueden analizar como sistemas religiosos y cómo los performances de curación adquieren diferentes significados dependiendo de la persona. De esta manera, las causas de la enfermedad son interpretadas según su modelo explicativo, siendo también los procesos de cura a los cuales es sometida una persona. Por tanto, todo proceso chamánico y biomédico tiene sus propios elementos, parafernalias y ritos con los cuales son intervenidos los cuerpos de las personas para llevarlos a un estado liminal y así su percance pueda ser superado.

Young (1976) argumenta que en el significado dado a las dolencias se confirman las ideas que se tienen sobre el mundo real y cómo de esta manera se deben asumir las justificaciones de las enfermedades para su comprensión. En este itinerario, los episodios narrados por Enio tienen como responsables a agentes externos que actúan sobre su cuerpo, causándole molestias permanentes. Así, el rol ontológico sobre el significado de las enfermedades es aquel que en la vida de la persona da las razones y revitaliza sus experiencias para comprender los episodios de la enfermedad, como una subcategoría de eventos relacionados con 
los rituales y el mundo religioso, que terminan siendo las explicaciones que para él son reales sobre su padecimiento.

Por último, vale la pena mencionar que el caso de Enio y el modo en el cual fue asistido por el sistema de salud son poco usuales: las remisiones por lo general son más demoradas, al igual que las autorizaciones para las cirugías y procesos de cuidado de un posoperatorio. Sin embargo, en este artículo lo que se trata de resaltar es la visión propia de los indígenas amazónicos y cómo ven, viven y enfrentan a la enfermedad recorriendo a veces largos caminos para superarla $\mathrm{y}$ en los cuales se puede acceder a distintos e insospechados mecanismos para conseguir la cura.

\section{REFERENCIAS}

Agga Calderón, Lucio «Kaziya Buinaima», Katarzyna I. Wojtylak y Juan Álvaro Echeverri (2019). Murui: Naie jiyakino. El lugar de origen. The place of origin. Linguíftica $15, \mathrm{n}^{\circ} 1$, Special issue «Línguas indígenas: Artes da palavra / Indigenous Languages: Verbal arts». K. Stenzel y B. Franchetto (eds.), 50-87. Recuperado de https://revistas.ufrj.br/index.php/rl/article/view/25563

Arhem, Kaj, Luis Cayón, Gladis Angulo y Maximiliano García (2004). Etnografía makuna. Instituto Colombiano de Antropología e Historia (ICANH). Colombia: Imprenta Nacional.

Cayón, Luis (2002). En las aguas del Yuruparí: cosmología y chamanismo makuna. Bogotá: Uniandes.

Chaumeil, Jean Pierre (1998). Ver, saber, poder, chamanismo entre los yagua de la Amazonia peruana. Lima: Institut Français d'ètudes andines, Centro Amazónico de Antropología y Aplicación Práctica CAAAP, Centro Argentino de Etnología Americana (CAEA).

Correa, François (1996). Por el camino de la anaconda remedio. Dinámica de la organización social entre los taiwano del Vaupés. Santafé de Bogotá: Tercer Mundo Editores.

Douglas, Mary (1966). Purity and Danger. An Analysis of concepts of pollution and taboo. Londres: Routledge y Kegan Paul Ed.

Echeverri, J. A. y O. Roman-Jitdutjaaño (2011). Witoto ash salts from the Amazon. Journal of Ethnopharmacology, 138(2), 492-502. https://doi.org/ 10.1016/j. jep.2011.09.047

Echeverri, Juan Álvaro (2012). Book review: Por donde hay soplo: estudios amazónicos en los países andinos (J. P. Chaumeil, O. Espinosa y M. Cornejo, 2012). Mundo Amazónico, 3, 294-299. 
Franky, Carlos (2004). Territorio y territorialidad indígena. Un estudio de caso entre los tanimuka del bajo Apaporis (Amazonia colombiana) (tesis de maestría en Estudios Amazónicos). Universidad Nacional de Colombia, Sede Amazonia.

Guhl Samudio, Juan Felipe (2005). El chamanismo y su relación con la medicina occidental. Historia y estrategias (monografía de pregrado para optar al título de antropólogo). Facultad de Ciencias Sociales. Universidad de los Andes.

Guhl Samudio, Juan Felipe (2008). La curación Lawichú y la prevención Ijají, en las comunidades indígenas del río Mirití-Paraná, Amazonas, Colombia (tesis de maestría). Universidad Nacional de Colombia

Guhl Samudio, Juan Felipe (2018). Los meandros de la salud en la Amazonia colombiana. Chamanismo, fecundación de los mundos y la intermedicalidad entre los Yukuna, Matapi, Letuama y Tanimuka, del río Mirití-Paraná (tesis doctoral). Universidad Nacional de Colombia.

Hildebrand, Martin von (1983). Medicina, chamanismo y botánica. Cosmovisión y el concepto de enfermedad entre los Ufaina. Bogotá: Presencia.

Hildebrand, Martin von (1987). Datos etnográficos sobre astronomía de los indígenas tanimuka del noroeste amazónico. En Jorge Arias de Grife y Elizabeth Reichel D. (comps.), Etnoastronomías americanas. Bogotá: Universidad Nacional de Colombia.

Karadimas, Dimitri (2011). Historias de diablos, mitos de avispas: acercamiento iconográfico a una unificación regional. En François Correa Rubio, Jean-Pierre Chaumeil y Roberto Pineda Camacho (eds.), El aliento de la memoria: antropología e historia en la Amazonia Andina. Bogotá: Congreso Internacional de Antropología Amazónica «Memoria Amazónica en los Países Andinos».

Karadimas, Dimitri (2012). Olor, calor, dolor: Noción de salud y enfermedad entre los Miraña del Caquetá. Amazonía Peruana, XIII(26), 73-118.

Kleinman, Arthur (1980). Patients and Healders in the context of culture. An exploration of Borderland between Anthropology, Medicine, And Phychiatry. Los Ángeles: University of California Press.

Langdon, E. Jean (2014). La negociación de lo oculto. Chamanismo, medicina y familia entre los siona del Bajo Putumayo. Popayán: Universidad del Cauca.

Mahecha, Dany (2004). Formación de MASA GORO «personas verdaderas». Pautas de crianza entre los Macuna del bajo Apaporis (tesis de maestría). Universidad Nacional de Colombia, Instituto IMANI.

Menéndez, Eduardo (2005). Intencionalidad, experiencia y función: la articulación de los saberes médicos. Revista de Antropología Social, 14, 33-69. Recuperado de https://revistas.ucm.es/index.php/RASO/article/view/RASO0505110033A/9403 
Pineda Camacho, Roberto (2014). Los huérfanos de la Vorágine: los andoques y su desafio para superar el llanto del genocidio cauchero. Bogotá: Academia Colombiana de Historia.

Reichel-Dolmatoff, Gerardo (1968). Desana: simbolismo de los indios tukano del Vaupés. Bogotá: Uniandes.

Reichel Dussan de von Hildebrand, Elizabeth (1987). Astronomía Yukuna Matapi. En Jorge Arias de Greiff y Elizabeth Reichel (eds.), Etnoastronomías amerindias (pp. 193-232). Bogotá: Universidad Nacional de Colombia.

Robayo, Camilo (2007). La concepción de la persona Inau'ké y del pensamiento ripechu de los Yukuna Matapí (tesis de doctorado). Philipps Universität, Instituto de Etnología, Facultad de Ciencias Sociales y Filosofía, Malburg.

Schauer, Stanley, Junia Schauer, Eladio Yukuna y Walter Yukuna (2005). Meke kemakánaka puráka'aloji, wapura'akó chu, eyá karíwana chu: Diccionario bilingüe yukuna-español español-yukuna. Bogotá: Fundación para el Desarrollo de los Pueblos Marginados (Instituto Lingüístico de Verano).

Van der Hammen, María Clara (1987). El manejo del mundo, naturaleza y sociedad entre los Yukuna de la Amazonia colombiana. Bogotá: Tropenbos.

Viveiros de Castro, Eduardo (2007). La selva de cristal: notas sobre la ontología de los espíritus amazónicos. Amazonía Peruana, XV(30), 85-110.

Viveiros de Castro, Eduardo (2017). A inconstancia da alma selvagem: E outros ensaios de antropologia. São Paulo: Ubu.

Young, A. (1976). Some implications of medical beliefs and practices for social anthropology. Am Anthropol, 78(1), 5-24. 